\title{
Anti-Estrogen Receptor Antibody
}

National Cancer Institute

\section{Source}

National Cancer Institute. Anti-Estrogen Receptor Antibody. NCI Thesaurus. Code

C118805.

Any antibody that recognizes estrogen receptor protein. 